\title{
Correlates of disease-specific knowledge in Chinese patients with COPD
}

This article was published in the following Dove Press journal:

International Journal of COPD

14 September 2016

Number of times this article has been viewed

\section{Carlos KH Wong' \\ WC Yu}

'Department of Family Medicine and Primary Care, The University of Hong Kong, ${ }^{2}$ Department of Medicine and Geriatrics, Princess Margaret Hospital, Hong Kong, Special Administrative Region
Correspondence: WC Yu

Department of Medicine and Geriatrics, Princess Margaret Hospital, Hong Kong Hospital Authority, Hong Kong, Special Administrative Region

Tel +852 29903737

Fax +852 29903333

Email yuwc@ha.org.hk
Background: This study aimed to determine the associations of various sociodemographic factors with the level of disease-specific knowledge among Hong Kong Chinese patients with COPD.

Methods: A cross-sectional survey of 100 Chinese adults with COPD recruited from outpatient clinics was conducted from September 2009 to September 2010. Data on the knowledge specific to COPD and patients' sociodemographics were collected from face-to-face interviews. Primary outcome of disease-specific knowledge was measured using 65-item Bristol COPD Knowledge Questionnaire (BCKQ), summing up the 65 items as the BCKQ overall score. Associations of sociodemographic factors with the BCKQ overall score were evaluated using the linear regression model.

Results: The mean BCKQ overall score of our patients was 41.01 (SD: 10.64). The knowledge in topics of "Smoking" and "Phlegm" achieved the first (3.97, SD: 0.82) and second (3.91, SD: 1.17) highest mean scores, respectively, while the topic of "Oral steroids" returned the lowest mean score of 1.89 (SD: 1.64). The BCKQ overall score progressively declined $(P<0.001)$ with increase in education level, with the highest BCKQ overall score of 46.71 at no formal education among all subgroups. Compared to nondrinkers, current drinkers were associated with lower total BCKQ score.

Conclusion: We found that among COPD patients in outpatient clinics, impairments in the level of COPD knowledge were evident in patients who were current drinkers or had higher level of education.

Keywords: knowledge, COPD, BCKQ, education, Chinese

\section{Background}

COPD is a disease posing a heavy burden and expenditure in the health care system worldwide. ${ }^{1,2}$ While mortality due to the major illnesses is declining, death attributable to COPD continues to rise and is projected to be the third major killer by $2020 .{ }^{3}$ In Hong Kong, COPD patients currently occupies $\sim 8 \%$ of all medical beds and ranks fourth in the cause of death. ${ }^{4}$

COPD is a chronic illness and its clinical management involves a multidisciplinary approach with numerous treatment modalities over a long period of time. Like many other chronic illnesses, self-management is important in COPD. For a successful self-management plan, the patients themselves should be equipped with sound knowledge of the disease and its treatments. Not surprisingly, patient education is an integral element of COPD management in international guidelines such as the Global Initiative for Chronic Obstructive Lung Disease (GOLD) ${ }^{5}$ and COPD foundation ${ }^{6}$ guidelines. Identification of patient factors that have significant impact on COPD knowledge enables the service provider to tailor-make educational materials 
to fit certain group of patients. Furthermore, knowing which areas of knowledge are particularly deficient in study cohorts may enable improvement of overall educational content. The ultimate goal is to facilitate self-management practices necessary for optimal control of the disease. Several systematic reviews ${ }^{7-9}$ of structured education intervention for COPD have emphasized the evaluation of health outcomes with respect to service utilization, health-related quality of life, spirometric indices, and particularly knowledge level. Published reports examining the comprehensive profile on patients' knowledge with respect to COPD are available, ${ }^{10-12}$ with one of these showing the beneficial effects of education interventions with increase in knowledge specific to COPD. ${ }^{10}$ Besides the deficiency in overall COPD knowledge, ${ }^{13}$ understanding and knowledge related to COPD pathophysiology was rather deficient in COPD patients in both outpatient and inpatient settings among Western populations. ${ }^{12}$ However, there were scanty data on the level of patients' knowledge of COPD and factors affecting the knowledge of COPD among Chinese population.

This study assessed the disease-specific knowledge of Chinese patients with COPD in Hong Kong and examined the associations between knowledge and characteristics of COPD patients. We hypothesize that patients who had received COPD education within the previous 2 years possess better COPD knowledge compared to those who never had received COPD education and that higher knowledge of COPD would be associated with higher education level.

\section{Subjects and methods}

A cross-sectional study was conducted in the Kwai Tsing district of the Kowloon West Cluster of the Hong Kong Hospital Authority, between September 2009 and September 2010. There were two target groups: 40 patients who had undergone COPD education as part of an outpatient pulmonary rehabilitation program within 2 years and 60 patients who never received any (in our institution, COPD education was not offered in usual care). Otherwise, patients were randomly selected from family medicine clinics, general outpatient clinics, and specialist clinics and screened for suitability to be recruited into the study. Inclusion criteria were having a diagnosis of COPD and receiving treatments for COPD, had spirometry within 12 months of screening showing postbronchodilator forced expiratory volume in 1 second $\left(\mathrm{FEV}_{1}\right)$ to forced vital capacity (FVC) ratio $<0.7$, and willing to participate in the study. If no spirometry data within 1 year were available, one would be performed at the screening visit. All spirometry tests were done according to the American Thoracic Society guidelines ${ }^{14}$ using local reference values. ${ }^{15}$
Patients were excluded if they had significant coexisting respiratory disease (eg, kyphoscoliosis, lung fibrosis, bronchiectasis), significant cognitive impairment from any cause, poor vision, or were illiterate.

Written informed consent was obtained from all recruited patients, who were then invited to attend the PMH Respiratory Research Clinic once to perform study-related procedures. During the study visit, sociodemographic information, including sex, age, education level, smoking status, drinking status, and working status, was collected. Patients were asked to self-report diagnoses of hypertension, diabetes mellitus, benign prostatic hypertrophy, tuberculosis, and stroke. Patients were also identified if they had ever received COPD education or attended COPD classes taught by respiratory nurses or allied health staff. Patients then completed the traditional Chinese version of the BCKQ. Interviewers ensured that all 65 questions were answered so as to avoid missing values. After the study visit, the patients continued to attend follow-up at their original clinics.

\section{Study instrument}

The primary outcome of disease-specific knowledge was measured using the Bristol COPD Knowledge Questionnaire (BCKQ), which was developed by White et $\mathrm{al}^{13}$ and published in 2006. Earlier, we engaged a professional service to translate this questionnaire into a traditional Chinese version. There were five steps in the process: forward translation, backward translation, review of the traditional Chinese version by clinician, cognitive debriefing, and final proof-reading. The BCKQ is a 65-item instrument extensively assessing the level of knowledge and understanding relating to COPD, aggregating 13 knowledge topics: 1) epidemiology, 2) etiology, 3) symptoms, 4) breathlessness, 5) phlegm, 6) infections, 7) exercise, 8) smoking, 9) vaccination, 10) inhaled bronchodilators, 11) antibiotics, 12) oral steroids, and 13) inhaled steroids. Each topic has five items, and for each item, there are three response options "True", "False", and "Don't know". A correct answer scores one points, while an incorrect answer or "don't know" scores zero point. Therefore, each topic has a score ranging from 0 to 5 , and the total score which sums up the scores of all 13 topics ranges from 0 to 65 . Permission to use the English version of BCKQ has been obtained from the copyright owner.

\section{Statistical analysis}

Descriptive statistics of sociodemographic and clinical characteristics of patients were presented in terms of mean and standard deviation (SD) for continuous variables and 
count and proportion for categorical variables. Proportions of patients giving correct answers for each item and for each knowledge topic were calculated. Mean and SD of the 13 knowledge topic score and total score were shown for comparisons with international literature about the diseasespecific knowledge of COPD patients. Linear regressions were performed to explore the associations between diseasespecific knowledge and patients' characteristics.

Data were analyzed using SPSS Windows Version 21.0 (IBM Corporation, Armonk, NY, USA). $P$-value of $<0.05$ was considered as statistically significant.

The study was approved by the Hospital Authority Kowloon West Cluster Research Ethics Committee.

\section{Results}

From October 2009 to September 2010, 49 patients were targeted for recruitment into the COPD-educated group and 40 were recruited and analyzed, while 80 were targeted for recruitment into the non-COPD-educated group and 60 were analyzed. Details of subject recruitment and exclusion are shown in Figure 1. Written informed consent was obtained from all enrolled patients. The sociodemographic and clinical characteristics of all patients are shown in Table 1. Of those, 91\% were male, and the mean age was 72.29 years with an SD of 6.75. A large proportion of patients (81\%) were ex-smokers, while $3 \%$ and $16 \%$ were nonsmokers and current smokers, respectively. Most of the patients were nondrinkers (57\%), which was more than ex-drinkers (37\%) and current drinkers $(6 \%)$. Most patients received primary education $(61 \%)$, which was more than those receiving no formal $(21 \%)$, secondary $(15 \%)$, and postsecondary

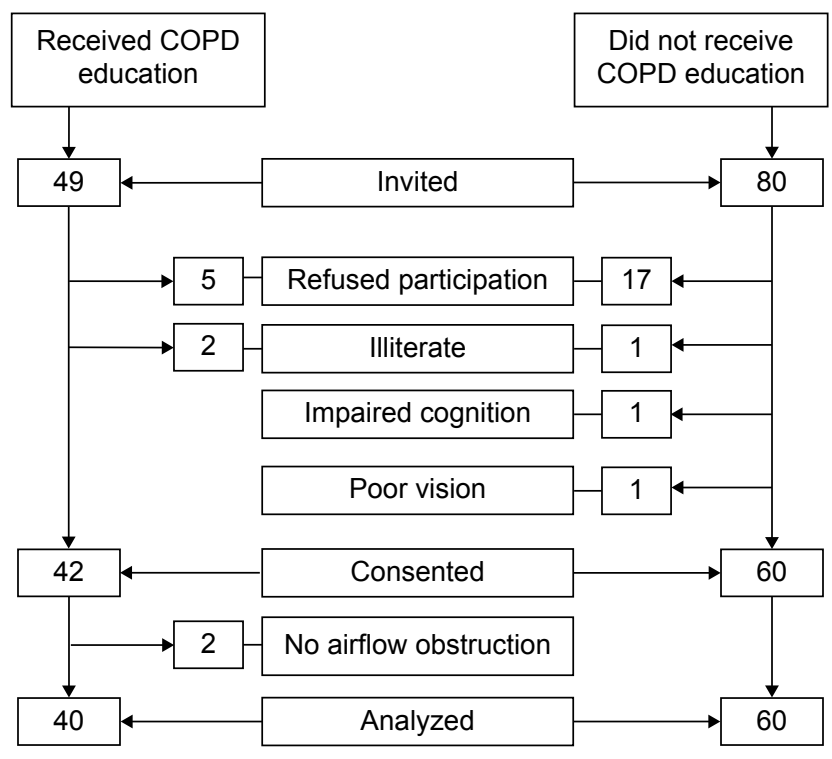

Figure I Flowchart on the subject recruitment, exclusion and enrollment. education $(3 \%)$. The majority $(92 \%)$ of patients has retired from work and had some form of self-reported comorbidity. Mean postbronchodilator $\mathrm{FEV}_{1}$ was $0.92 \mathrm{~L}$ (SD: 0.43) and $41.8 \%$ predicted (SD: 18.86 ), while the mean postbronchodilator $\mathrm{FEV}_{1} / \mathrm{FVC}$ ratio was 0.44 (SD: 0.12). Using the GOLD severity staging according to percent predicted $\mathrm{FEV}_{1}, 71 \%$ of subjects had severe $(38 \%)$ and very severe $(33 \%)$ stages of COPD.

The percentages of subjects giving correct response for each of the 65 items and 13 knowledge topics are displayed in Table 2. Of the 65 BCKQ items, item 7a "Walking is better exercise than breathing exercises to improve fitness" and item $8 \mathrm{a}$ "Stopping smoking will reduce the risk of heart disease" had the first and second greatest percentages (100\% and 98\%) of subjects giving a correct response, respectively, whereas item 4a "Severe breathlessness prevents travel by air" had the lowest percentage of $6 \%$. Among the 13 knowledge topics, the eighth topic "Smoking" and the fifth topic "Phlegm" had the first and second greatest percentages (79.6\% and 78.2\%) of correct response, respectively, while the 12th topic "Oral steroids" had the lowest (37.8\%). Table 3 presents the BCKQ overall score and knowledge scores of all the 13 topics. The mean and median of BCKQ overall of our patients were 41.01 (SD: 10.64) and 42.50, respectively. In line with the percentages of correct response, the topics of "Smoking" and "Phlegm" achieved the first (3.97, SD: 0.82) and second (3.91, SD: 1.17) highest mean scores, respectively, while the topic of "Oral steroids" returned the lowest mean score of 1.89 (SD: 1.64). Nine out of all topics (except "Phlegm", "Exercise", "Smoking", and "Inhaled bronchodilators") had the full coverage attaining the lowest (zero) and highest (five) possible scores.

Table 4 displays the mean and SD of BCKQ overall score in each subgroup and the regression coefficients estimating the effects of the sociodemographic and clinical characteristics on BCKQ overall scores. The BCKQ overall scores progressively decline $(P<0.001)$ with increase in education level, with the highest BCKQ overall score of 46.71 at no formal education among all subgroups. Compared to no formal education, patients achieving primary, secondary, and postsecondary education had overall BCKQ scores of -5.906 (95\% CI: -11.148 to $-0.664, P=0.027),-8.005$ (95\% CI: -15.309 to $-0.700, P=0.032)$, and $-23.021(95 \%$ CI: -35.028 to $-11.015, P<0.001)$, respectively. Drinking status was associated $(P=0.020)$ with overall COPD knowledge: nondrinkers had higher BCKQ overall scores than current drinkers, having a decrement of $13.006(95 \%$ CI: -22.236 to $-3.776, P=0.006)$. On the other hand, none of the measured clinical characteristics, including the 
Table I Sociodemographic and clinical characteristics of 100 subjects

\begin{tabular}{|c|c|c|c|c|}
\hline \multirow[t]{2}{*}{ Characteristics } & \multirow{2}{*}{$\begin{array}{l}\text { Total } \\
(\mathbf{N}=\mid 00)\end{array}$} & \multicolumn{2}{|c|}{ Received COPD education } & \multirow[t]{2}{*}{$P$-value } \\
\hline & & Yes $(\mathrm{N}=40)$ & No $(\mathrm{N}=60)$ & \\
\hline \multicolumn{5}{|l|}{ Sociodemographic } \\
\hline Age $(y r$, mean $\pm S D)$ & $72.29 \pm 6.75$ & $72.78 \pm 5.61$ & $71.97 \pm 7.45$ & 0.560 \\
\hline Male $(\%)$ & 91 & 36 & 55 & 0.775 \\
\hline Education (\%) & & & & 0.318 \\
\hline No formal school & 21 & 7 & 14 & \\
\hline Primary & 61 & 25 & 36 & \\
\hline Secondary & 15 & 8 & 7 & \\
\hline Postsecondary & 3 & 0 & 3 & \\
\hline Smoking status (\%) & & & & 0.010 \\
\hline Nonsmoker & 3 & 1 & 2 & \\
\hline Ex-smoker & 81 & 38 & 43 & \\
\hline Current smoker & 16 & 1 & 15 & \\
\hline Drinking (\%) & & & & 0.059 \\
\hline Nondrinker & 57 & 27 & 30 & \\
\hline Ex-drinker & 37 & 13 & 24 & \\
\hline Current drinker & 6 & 0 & 6 & \\
\hline Retired from working (\%) & 92 & 37 & 55 & 0.880 \\
\hline Recruited from Medical SOPC (\%) & 20 & 0 & 20 & $<0.001$ \\
\hline \multicolumn{5}{|l|}{ Clinical characteristics } \\
\hline $\mathrm{FEV}_{1}$ (liters, mean $\pm \mathrm{SD}$ ) & $0.92 \pm 0.43$ & $0.68 \pm 0.36$ & $1.07 \pm 0.40$ & $<0.001$ \\
\hline $\mathrm{FEV}_{1}(\%$ predicted, mean $\pm \mathrm{SD})$ & $41.80 \pm 18.86$ & $32.03 \pm 16.18$ & $48.32 \pm|7.6|$ & $<0.001$ \\
\hline $\mathrm{FEV}_{\mathrm{l}} / \mathrm{FVC}($ mean $\pm \mathrm{SD})$ & $0.44 \pm 0.12$ & $0.39 \pm 0.11$ & $0.48 \pm 0.12$ & $<0.001$ \\
\hline GOLD severity staging (\%) & & & & $<0.001$ \\
\hline Stage I, mild & 2 & 0 & 2 & \\
\hline Stage II, moderate & 27 & I & 26 & \\
\hline Stage III, severe & 38 & 14 & 24 & \\
\hline Stage IV, very severe & 33 & 25 & 8 & \\
\hline \multicolumn{5}{|l|}{ Past history (\%) } \\
\hline $\mathrm{HT}$ & 40 & 15 & 25 & 0.677 \\
\hline DM & 13 & 2 & 11 & 0.052 \\
\hline $\mathrm{BPH}$ & 24 & 9 & 15 & 0.774 \\
\hline TB & 13 & 5 & 8 & 0.903 \\
\hline Stroke & 2 & 1 & I & 0.77। \\
\hline
\end{tabular}

Abbreviations: yr, years; SD, standard deviation; SOPC, specialist outpatient clinic; FEV, forced expiratory volume; FVC, forced vital capacity; GOLD, Global Initiative for Chronic Obstructive Lung Disease; HT, hypertension; DM, diabetes mellitus; BPH, benign prostatic hyperplasia; TB, tuberculosis.

attendance of COPD education, were associated with overall COPD knowledge.

\section{Discussion}

This is the first study that used a validated instrument to assess knowledge level in ethnic Chinese patients and examined the associated clinical and sociodemographic characteristics. The BCKQ demonstrated strengths in knowledge in the topics of smoking and phlegm with a mean score of 3.97 (79.4\%) and 3.91 (78.2\%), respectively. Likewise, it revealed gaps in knowledge in the topic of oral steroids with only a mean score of 1.88 (37.6\%). We examined our education contents and did find this topic to be inadequately covered. Such deficiency of knowledge about their own chronic illness is indicative of inadequate health literacy among the study subjects, given the strong correlations of the knowledge level with health literacy among patients with not only COPD ${ }^{16}$ but also other chronic diseases. ${ }^{17,18}$ Having identifying areas with weak knowledge level, enhancement in these areas is warranted in future education materials and classes.

Putting in the same metric of BCKQ overall score, the knowledge level of both the COPD patients and health care professionals managing those patients was available for comparison. In a UK study, ${ }^{19}$ the BCKQ was administered to health care professionals involved in the service delivery of COPD intervention in primary and secondary care. Not surprisingly, the BCKQ overall score of health care professionals had a higher mean score than that of COPD patients (mean: 50 vs 41). The topics of breathlessness and medications scored worst for the health care professionals. In the knowledge topic of inhaled steroids, it is interesting and worrying that COPD patients had greater knowledge score 
Table 2 Percentage of subjects giving a correct response for all 65 items and 13 topics

\begin{tabular}{|c|c|c|c|c|c|c|c|}
\hline $\mathbf{Q}$ & Topic & $\mathbf{a}$ & b & c & d & e & Total \\
\hline \multirow[t]{2}{*}{ I } & Epidemiology & 42 & 74 & 84 & 69 & 55 & 64.8 \\
\hline & & $\mathrm{F}$ & $T$ & $\mathrm{~T}$ & $F$ & $\mathrm{~T}$ & \\
\hline \multirow[t]{2}{*}{2} & Etiology & 88 & 86 & 73 & 18 & 69 & 66.8 \\
\hline & & $\mathrm{T}$ & $\mathrm{T}$ & $\mathrm{T}$ & $F$ & $\mathrm{~F}$ & \\
\hline \multirow[t]{2}{*}{3} & Symptoms & 48 & 73 & 84 & 50 & 39 & 58.8 \\
\hline & & $\mathrm{F}$ & $T$ & $\mathrm{~T}$ & $\mathrm{~F}$ & $\mathrm{~F}$ & \\
\hline \multirow[t]{2}{*}{4} & Breathlessness & 6 & 63 & 86 & 89 & 93 & 67.4 \\
\hline & & $\mathrm{F}$ & $T$ & $\mathrm{~F}$ & $\mathrm{~T}$ & $\mathrm{~T}$ & \\
\hline \multirow[t]{2}{*}{5} & Phlegm & 86 & 84 & 65 & 84 & 72 & 78.2 \\
\hline & & $\mathrm{T}$ & $T$ & $\mathrm{~T}$ & $\mathrm{~F}$ & $\mathrm{~T}$ & \\
\hline \multirow[t]{2}{*}{6} & Infections & 39 & 85 & 67 & 31 & 65 & 57.4 \\
\hline & & $\mathrm{F}$ & $T$ & $\mathrm{~T}$ & $\mathrm{~F}$ & $\mathrm{~F}$ & \\
\hline \multirow[t]{2}{*}{7} & Exercise & 100 & 45 & 83 & 84 & 3 & 63.0 \\
\hline & & $\mathrm{T}$ & $\mathrm{F}$ & $\mathrm{T}$ & $\mathrm{T}$ & $\mathrm{F}$ & \\
\hline \multirow[t]{2}{*}{8} & Smoking & 98 & 95 & 41 & 94 & 70 & 79.6 \\
\hline & & $T$ & $T$ & $\mathrm{~F}$ & $\mathrm{~F}$ & $\mathrm{~F}$ & \\
\hline \multirow[t]{2}{*}{9} & Vaccination & 93 & 33 & 59 & 60 & 42 & 57.4 \\
\hline & & $\mathrm{T}$ & $\mathrm{F}$ & $\mathrm{F}$ & $\mathrm{F}$ & $\mathrm{T}$ & \\
\hline \multirow[t]{2}{*}{10} & Inhaled bronchodilators & 91 & 60 & 59 & 74 & 68 & 70.4 \\
\hline & & $\mathrm{F}$ & $\mathrm{T}$ & $\mathrm{F}$ & $\mathrm{T}$ & $\mathrm{T}$ & \\
\hline \multirow[t]{2}{*}{ II } & Antibiotics & 55 & 67 & 43 & 52 & 86 & 60.6 \\
\hline & & $\mathrm{F}$ & $T$ & $\mathrm{~F}$ & $\mathrm{~F}$ & $\mathrm{~T}$ & \\
\hline \multirow[t]{2}{*}{12} & Oral steroids & 33 & 35 & 59 & 34 & 28 & 37.8 \\
\hline & & $\mathrm{F}$ & $\mathrm{F}$ & $\mathrm{T}$ & $\mathrm{T}$ & $\mathrm{T}$ & \\
\hline \multirow[t]{2}{*}{13} & Inhaled steroids & 43 & 72 & 57 & 51 & 71 & 58.8 \\
\hline & & $\mathrm{F}$ & $\mathrm{F}$ & $\mathrm{T}$ & $\mathrm{F}$ & $\mathrm{F}$ & \\
\hline \multicolumn{2}{|c|}{ Overall } & & & & & & 63.2 \\
\hline
\end{tabular}

Notes: $\mathrm{F}=$ "false" as correct response; $\mathrm{T}$ = "true" as correct response.

(mean: 2.95 vs 2.70 ; correct $\%: 59.0 \%$ vs $54.0 \%$ ) than health care professionals.

This study showed that knowledge of COPD in Hong Kong Chinese was deficient, especially in highly educated subjects. In contrast to conventional perception, adjusted

Table 3 Knowledge scores representing the total number of correct responses for all 13 topics and overall

\begin{tabular}{llllll}
\hline $\mathbf{Q}$ & Topic & Mean & SD & Median & $\begin{array}{l}\text { Range } \\
\text { (Min-Max) }\end{array}$ \\
\hline I & Epidemiology & 3.24 & 1.16 & 3.00 & $0.00-5.00$ \\
2 & Etiology & 3.34 & 1.05 & 3.00 & $0.00-5.00$ \\
3 & Symptoms & 2.94 & 1.43 & 3.00 & $0.00-5.00$ \\
4 & Breathlessness & 3.37 & 0.99 & 4.00 & $0.00-5.00$ \\
5 & Phlegm & 3.91 & 1.17 & 4.00 & $1.00-5.00$ \\
6 & Infections & 2.87 & 1.48 & 3.00 & $0.00-5.00$ \\
7 & Exercise & 3.14 & 0.86 & 3.00 & $1.00-5.00$ \\
8 & Smoking & 3.97 & 0.82 & 4.00 & $2.00-5.00$ \\
9 & Vaccination & 2.87 & 1.23 & 3.00 & $0.00-5.00$ \\
I0 & Inhaled bronchodilators & 3.51 & 1.16 & 4.00 & $1.00-5.00$ \\
II & Antibiotics & 3.02 & 1.52 & 3.00 & $0.00-5.00$ \\
I2 & Oral steroids & 1.89 & 1.64 & 2.00 & $0.00-5.00$ \\
I3 & Inhaled steroids & 2.94 & 1.63 & 3.00 & $0.00-5.00$ \\
BCKQ overall & 41.01 & 10.64 & 42.50 & $15.00-63.00$ \\
\hline
\end{tabular}

Abbreviations: BCKQ, Bristol COPD Knowledge Questionnaire; Min, minimum; Max, maximum. analysis demonstrated the inverse association of education level with the BCKQ overall score and urged caution on the intuitive thinking that lower level of education in COPD patients would be associated with poorer COPD knowledge. There is no ready explanation for this finding, but one might speculate that this is a tortoise-rabbit race scenario in which those who had higher education pay less attention to the education materials. This finding underlined the enhancement on communication and transfer of COPD knowledge from health professionals to patients and thus the unmet need for the structured self-management education program for highly educated patients with COPD. In educating those patients, their level of knowledge is an important short-term outcome of self-management education intervention because the increase in the knowledge level may act as a mediator of the improvement in long-term clinical outcomes of hospitalization, exacerbation frequency, and management.

Another study conducted in Hong Kong ${ }^{20}$ reported the underprovision of education intervention, as low as $18 \%$, in the clinical management of COPD patients, suggesting the urgent need to improve accessibility to education intervention among COPD patients, regardless of education level. Disappointingly, attendees of COPD education exhibited a decrease, albeit insignificantly, in COPD knowledge compared to nonattendees. These findings call for a critical review of the content and conduct of existing COPD education programs, with particular emphasis on the weaker knowledge topic observed in this study. However, it would be premature to conclude that the current COPD education program is ineffective, since we did not directly measure change in knowledge level before and after such program.

Besides education level, nondrinkers were observed to have a significantly higher BCKQ overall score in our study. There is little evidence that the current drinker had lower acquired knowledge than nondrinker among patients with chronic disease. It was postulated that frequent drinkers (low-risk drinking is defined as no more than three drinks in any single day and no more than seven drinks per week for women, and no more than four drinks in any single day and no more than 14 drinks per week for men ${ }^{21}$ ) may have less self-efficacy and awareness than nondrinkers who indicated a high level of knowledge. However, those variables were not measured in our study to justify the interrelationships among them.

Several limitations in our study should be noted. First, the total number of subjects is small, with reduced statistical power to identify additional potentially significant factors. Second, we did not randomly choose our study subjects who had undergone some form of COPD education because 40 is 
Table 4 Factors associated with BCKQ overall score

\begin{tabular}{|c|c|c|c|c|c|}
\hline \multirow[t]{2}{*}{ Factors $^{a}$} & \multirow[t]{2}{*}{ Mean } & \multirow[t]{2}{*}{ SD } & \multicolumn{3}{|c|}{ BCKQ overall score } \\
\hline & & & Coefficient & $95 \% \mathrm{Cl}$ & $P$-value \\
\hline \multicolumn{6}{|l|}{ Sociodemographic characteristics } \\
\hline Age $(y r)$ & & & -0.072 & $(-0.408,0.263)$ & 0.672 \\
\hline \multicolumn{6}{|l|}{ Sex } \\
\hline Female & 38.56 & 8.83 & & & \\
\hline Male & 41.25 & 10.81 & 2.921 & $(-5.453,11.296)$ & 0.494 \\
\hline Education (no formal school) & 46.71 & $|1.5|$ & & & 0.001 \\
\hline Postsecondary & 26.67 & 3.79 & -23.021 & $(-35.028,-11.015)$ & $<0.001$ \\
\hline Secondary & 37.20 & 8.93 & -8.005 & $(-15.309,-0.700)$ & 0.032 \\
\hline Primary & 40.69 & 9.90 & -5.906 & $(-11.148,-0.664)$ & 0.027 \\
\hline Smoking (nonsmoker) & 41.00 & 9.85 & & & 0.744 \\
\hline Current smoker & 43.31 & 10.22 & 4.968 & $(-9.947,19.882)$ & 0.514 \\
\hline Ex-smoker & 40.56 & 10.80 & 3.026 & $(-10.510,16.562)$ & 0.661 \\
\hline Drinking (nondrinker) & 41.53 & 9.52 & & & 0.020 \\
\hline Current drinker & 30.83 & 5.49 & -13.006 & $(-22.236,-3.776)$ & 0.006 \\
\hline Ex-drinker & 41.86 & 12.14 & -1.990 & $(-6.143,2.163)$ & 0.348 \\
\hline Retired from working (No) & 39.13 & 7.02 & & & \\
\hline Yes & 41.17 & 10.91 & 3.296 & $(-4.216,10.808)$ & 0.390 \\
\hline Recruited from medical SOPC (No) & 40.35 & 10.92 & & & \\
\hline Yes & 43.65 & 9.21 & 0.441 & $(-5.176,6.058)$ & 0.878 \\
\hline \multicolumn{6}{|l|}{ Clinical characteristics } \\
\hline $\mathrm{FEV}_{1}$ in \% predicted & & & 0.025 & $(-0.116,0.165)$ & 0.730 \\
\hline Received COPD education (No) & 40.28 & 10.76 & & & \\
\hline Yes & 41.50 & 10.61 & -1.752 & $(-7.041,3.537)$ & 0.516 \\
\hline COPD severity (Stage I/II) & 42.17 & 8.80 & & & 0.930 \\
\hline Stage III & 40.00 & 11.45 & -0.631 & $(-6.508,5.247)$ & 0.833 \\
\hline Stage IV & 41.15 & 11.33 & 0.231 & $(-7.567,8.029)$ & 0.954 \\
\hline History of HT (No) & 41.40 & 11.02 & & & \\
\hline Yes & 40.43 & 10.14 & -1.465 & $(-5.589,2.659)$ & 0.486 \\
\hline History of DM (No) & 40.77 & 10.32 & & & \\
\hline Yes & 42.62 & 12.91 & 2.548 & $(-3.611,8.707)$ & 0.417 \\
\hline History of BPH (No) & 40.95 & 10.43 & & & \\
\hline Yes & 41.21 & $11.5 \mid$ & 1.846 & $(-2.82|, 6.5| 3)$ & 0.438 \\
\hline History of TB (No) & 40.59 & 10.10 & & & \\
\hline Yes & 43.85 & 13.84 & 4.502 & $(-1.472,10.475)$ & 0.140 \\
\hline
\end{tabular}

Note: andicating the reference level of categorical variables in basket.

Abbreviations: BCKQ, Bristol COPD Knowledge Questionnaire; SD, standard deviation; Cl, confidence interval; yr, years; SOPC, specialist outpatient clinic; FEV, forced expiratory volume; HT, hypertension; DM, diabetes mellitus; BPH, benign prostatic hyperplasia; TB, tuberculosis.

the maximum number we could identify. Nonetheless, the 60 patients who had not undergone any COPD education were randomly selected. The result was that the two groups were not well matched in a number of clinical characteristics (Table 1). Third, it is possible that subjects who have undergone COPD education 1 month previously have better knowledge than those who did it 1 year or 2 years previously, and this is not addressed in our study. Finally, casual relationships were not established in this cross-sectional study. We cannot rule out the possibility that COPD knowledge was associated with drinking status and education level, and these should be examined in a longitudinal study.

\section{Conclusion}

There is marked overall deficiency of disease knowledge among our COPD patients, which appears not improved with the current COPD education programs. Impairments in the level of COPD knowledge were evident in patients who were current drinkers or had higher level of education.

\section{Acknowledgments}

We thank Ms Polly Pang and Ms Eva Tam for coordinating the study and administering the BCKQ and Ms Carmen Cheung for performing spirometry for our subjects. This study is supported by a research grant from GlaxoSmithKline Hong Kong Ltd.

\section{Disclosure}

Dr WC Yu received a research grant from GlaxoSmithKline Hong Kong Ltd for this study project. No other potential conflicts of interest relevant to this work were reported. 


\section{References}

1. Mannino DM, Buist AS. Global burden of COPD: risk factors, prevalence, and future trends. Lancet. 2007;370(9589):765-773.

2. Sullivan SD, Ramsey SD, Lee TA. The economic burden of COPD. Chest. 2000;117(2 Suppl):5S-9S.

3. Murray CJL, Lopez AD. Alternative projections of mortality and disability by cause 1990-2020: Global Burden of Disease Study. Lancet. 1997;349(9064):1498-1504.

4. Chan-Yeung M, Lai CKW, Chan K-S, et al; Hong Kong Thoracic Society. The burden of lung disease in Hong Kong: a report from the Hong Kong Thoracic Society. Respirology. 2008;13(Suppl 4):S133-S165.

5. goldcopd.org [webpage on the Internet]. Global Strategy for the Diagnosis, Management, and Prevention of Chronic Obstructive Pulmonary Disease; 2016. Available from: http://www.goldcopd.org/. Accessed August 5, 2016.

6. Rennard S, Thomashow B, Crapo J, et al. Introducing the COPD foundation guide for diagnosis and management of COPD, recommendations of the COPD foundation. COPD. 2013;10(3):378-389.

7. Blackstock F, Webster K. Disease-specific health education for COPD: a systematic review of changes in health outcomes. Health Educ Res. 2007;22(5):703-717.

8. Tan JY, Chen JX, Liu XL, et al. A meta-analysis on the impact of disease-specific education programs on health outcomes for patients with chronic obstructive pulmonary disease. Geriatr Nurs. 2012;33(4): 280-296.

9. Monninkhof E, van der Valk P, van der Palen J, van Herwaarden C, Partridge MR, Zielhuis G. Self-management education for patients with chronic obstructive pulmonary disease: a systematic review. Thorax. 2003;58(5):394-398.

10. Hill K, Mangovski-Alzamora S, Blouin M, et al. Disease-specific education in the primary care setting increases the knowledge of people with chronic obstructive pulmonary disease: a randomized controlled trial. Patient Educ Couns. 2010;81(1):14-18.

11. O’Neill B, Cosgrove D, MacMahon J, McCrum-Gardner E, Bradley JM. Assessing education in pulmonary rehabilitation: the understanding COPD (UCOPD) questionnaire. COPD. 2012;9(2):166-174.

12. Scott AS, Baltzan MA, Dajczman E, Wolkove N. Patient knowledge in chronic obstructive pulmonary disease: back to basics. COPD. 2011; 8(5):375-379.
13. White R, Walker P, Roberts S, Kalisky S, White P. Bristol COPD Knowledge Questionnaire (BCKQ): testing what we teach patients about COPD. Chron Respir Dis. 2006;3(3):123-131.

14. Qaseem A, Wilt TJ, Weinberger SE, et al; American College of Physicians; American College of Chest Physicians; American Thoracic Society; European Respiratory Society. Diagnosis and management of stable chronic obstructive pulmonary disease: a clinical practice guideline update from the American College of Physicians, American College of Chest Physicians, American Thoracic Society, and European Respiratory Society. Ann Intern Med. 2011;155(33):179-191.

15. Ip MS, Ko FW, Lau AC, et al; Hong Kong Thoracic Society; American College of Chest Physicians (Hong Kong and Macau Chapter). Updated spirometric reference values for adult Chinese in Hong Kong and implications on clinical utilization. Chest. 2006;129(2):384-392.

16. Sadeghi S, Brooks D, Stagg-Peterson S, Goldstein R. Growing awareness of the importance of health literacy in individuals with COPD COPD. 2013;10(1):72-78.

17. Williams MV, Baker DW, Parker RM, Nurss JR. Relationship of functional health literacy to patients' knowledge of their chronic disease: a study of patients with hypertension and diabetes. Arch Intern Med. 1998;158(2):166-172.

18. Gazmararian JA, Williams MV, Peel J, Baker DW. Health literacy and knowledge of chronic disease. Patient Educ Couns. 2003;51(3): 267-275.

19. Edwards K, Singh S. P235 the Bristol COPD Knowledge Questionnaire (BCKQ): assessing the knowledge of healthcare professionals involved in the delivery of COPD services. Thorax. 2012;67(Suppl 2):A167.

20. Yu WC, Tai E, Fu SN, et al. Treatment of patients with chronic obstructive pulmonary disease as practised in a defined Hong Kong community: a cross-sectional pilot survey. Hong Kong Med J. 2011;17(4): 306-316.

21. NIH [webpage on the Internet]. Overview of Alcohol Consumption Drinking Levels Defined. Available from: https://www.niaaa.nih. gov/alcohol-health/overview-alcohol-consumption/moderate-bingedrinking. Accessed July 18, 2016.
International Journal of COPD

\section{Publish your work in this journal}

The International Journal of COPD is an international, peer-reviewed journal of therapeutics and pharmacology focusing on concise rapid reporting of clinical studies and reviews in COPD. Special focus is given to the pathophysiological processes underlying the disease, intervention programs, patient focused education, and self management protocols.

\section{Dovepress}

This journal is indexed on PubMed Central, MedLine and CAS. The manuscript management system is completely online and includes a very quick and fair peer-review system, which is all easy to use. Visit http://www.dovepress.com/testimonials.php to read real quotes from published authors. 